\title{
PENGETAHUAN IBU TENTANG PEMANFAATAN TANAMAN OBAT UNTUK ASAM URAT
}

\author{
Indri Kusuma Dewi, Agus Winarso, Rapim Yuanditra \\ Kementerian Kesehatan, Politeknik Kesehatan Surakarta Jurusan Jamu
}

\begin{abstract}
Knowledge, PKK Plants, Drugs For Gout. The purpose of this study was to determine how the PKK knowledge about the use of herbs for uric acid in the village of Klaten Danguran South. This research is quantitative descriptive study, with cross sectional approach to the subject of this study is the PKK of 50 samples. Measuring tool used is a questionnaire. The results showed that the PKK knowledge about the use of herbs for uric acid in the village of Klaten Danguran South included in the category enough by $52 \%$, both by $38 \%$, and $10 \%$ less category. PKK knowledge about the use of medicinal plants for acid in the village of Klaten Danguran South in the category enough.
\end{abstract}

Keywords: Knowledge, PKK Plants, Drugs For Gout

\begin{abstract}
Abstrak: Pengetahuan, Ibu PKK Tanaman, Obat Untuk Asam Urat. Tujuan penelitian ini adalah untuk mengetahui bagaimana pengetahuan Ibu PKK tentang pemanfaatan tanaman obat untuk asam urat di Desa Danguran Klaten Selatan. Jenis penelitian ini merupakan penelitian deskriptif kuantitatif, dengan pendekatan cross sectional dengan subyek penelitian ini adalah Ibu PKK sebesar 50 sampel. Alat ukur yang digunakan adalah kuesioner. Hasil penelitian menunjukkan bahwa pengetahuan Ibu PKK tentang pemanfaatan tanaman obat untuk asam urat di Desa Danguran Klaten Selatan termasuk dalam kategori cukup sebesar 52\%, baik sebesar 38\%, dan kategori kurang sebesar 10\%. Pengetahuan Ibu PKK tentang pemanfaatan tanaman obat untuk asam di Desa Danguran Klaten Selatan dalam kategori cukup.
\end{abstract}

Kata Kunci: Pengetahuan, Ibu PKK Tanaman, Obat Untuk Asam Urat

\section{PENDAHULUAN}

Indonesia dikenal memiliki berbagai suku bangsa dan sebagian besar penduduknya masih tergantung pada sumber daya alam di sekitarnya. Sekitar 1200 jenis tumbuhan telah dimanfaatkan oleh masyarakat secara tradisional sebagai bahan obat (Setyowati, 2006).

Menurut Riset kesehatan dasar (Riskesdas) tahun 2010, menunjukkan bahwa $50 \%$ penduduk Indonesia menggunakan jamu baik untuk menjaga kesehatan maupun untuk pengobatan karena sakit. Data Riskesdas ini menunjukkan bahwa, jamu sebagai bagian dari pengobatan tradisional, telah diterima oleh masyarakat Indonesia (Riskesdas, 2010).

Meskipun pengobatan tradisional termasuk jamu, sudah banyak digunakan oleh tenaga kesehatan profesional maupun battra (pengobatan tradisional), namun banyak tenaga profesional kesehatan yang mempertanyakan pengobatan tradisional (jamu) dalam pelayanan 
kesehatan formal. Hal ini bisa dimengerti, karena sesuai dengan Undang-undang No. 29 tahun 2004 tentang Praktik Kedokteran, dokter atau dokter gigi dalam memberikan pelayanan kesehatan harus memenuhi standar pelayanan medis, yang pada prinsipnya harus memenuhi kaidah praktik kedokteran berbasis bukti (evidence based medicine).

Dipihak lain bukti-bukti ilmiah tentang mutu, keamanan dan manfaat pengobatan tradisional (jamu) dinilai belum adekuat untuk dapat dipraktikkan pada pelayanan kesehatan formal. Dengan kata lain, pengobatan tradisional (jamu) masih memerlukan bukti ilmiah yang cukup untuk dapat digunakan oleh tenaga profesional kesehatan. (Riskesdas,2010).

Pada Tahun 2006 tanaman obat Indonesia menduduki posisi sangat penting dalam dunia kesehatan. Pasalnya, di tengah kondisi dunia yang kurang menguntungkan, tanaman obat memberi solusi tepat menuju sehat secara alami, murah, mudah, dan aman. Semakin dipahami manfaatnya, masyarakat semakin terbiasa menggunakan tanaman obat dalam menghadapi berbagai keluhan dan gangguan kesehatan. Yang terpenting, tanaman obat di gunakan ternyata ada di sekitar kita. Demikian pula dengan gangguan rematik dan asam urat. Penyakit ini mudah menyerang, karena pola makan yang salah, yakni pola makan yang memberi ruang bagi kita untuk menonsumsi makanan pemicu asam urat (Tersonoadi, 2006).

Ilmu kedokteran berkembang pesat dan penelitian telah begitu banyak. tetapi, buah karya para ilmuwan itu kurang populer di tengah tengah masyarakat kita tentang pemanfaatan tanaman obat. Hal ini disebabkan oleh masalah komunikasi dan informasi serta pemahaman yang kurang benar dalam masyarakat kita tentang suatu penyakit. Pemahaman yang keliru mudah ditularkan dari satu orang ke orang lain dan diturunkan dari generasi ke generasi sehingga terlanjur melekat kuat dan sulit diubah (Soeroso et al, 2001).

Berdasarkan fenomena yang terjadi bahwa rendahnya pengetahuan tentang pemanfaatan tanaman obat untuk asam urat berdampak pada sikap masyarakat umum khususnya menggunakan tanaman obat ataupun obat tradisional. Obat Tradisional ialah obat yang berasal dari bahan tumbuhtumbuhan, hewan, mineral dan atau sediaan galeniknya atau campuran dari bahan-bahan tersebut yang belum mempunyai data klinis dan dipergunakan dalam usaha pengobatan berdasarkan pengalaman (Depkes RI, 1989). Obat tradisional dari tumbuhan masih berperan penting terhadap kesehatan masyarakat, terutama masyarakat yang hidup di pedalaman. Oleh karena itu perlu dilakukan penelitian tentang pengetahuan keanekaragaman hayati dan pemanfaatan tumbuhan sebagai bahan obat tradisional (Susiarti dkk, 2009).

Berdasarkan survey pendahuluan yang dilakukan di Desa Danguran dengan metode wawancara terdapat 5 dari 10 ibu PKK yang mengetahui tentang manfaat tanaman obat untuk asam urat. Oleh karena itu penulis tertarik untuk mengetahui tentang seberapa besar Pengetahuan Ibu PKK mengenai Pemanfaatan Tanaman Obat untuk Asam urat di Desa Danguran Klaten Selatan.

Pemanfaatan tanaman obat begitu banyak ditemukan. Namun, pembahasan karya tulis ilmiah ini 
dikhususkan pada pencegahan dan mengatasi asam urat dengan 5 tanaman obat untuk asam urat.

\section{METODE PENELITIAN}

Jenis penelitian ini adalah deskfriptif kuantitatif yaitu melakukan deskripsi atau gambaran mengenai fenomena yang ditemukan, hasil penelitian disajikan secara apa adanya (Sugiyono, 2011). Metode pendekatan yang digunakan cross sectional artinya penelitian menggambarkan suatu keadaan dimana objek penelitian hanya diteliti sekali saja dan dalam waktu tertentu secara bersamaan (Notoatmodjo, 2010).

Alat yang digunakan dalam penelitian ini berupa kuesioner. Kuesioner untuk mengungkap karakteristik responden meliputi identitas masyrakat dan pertanyaan yang berkaitan dengan Pemanfaatan tanaman obat untuk asam urat. Identitas masyarakat meliputi pendidikan, sumber informasi tentang pemanfaatan tanaman obat. dengan:

Jalannya penelitian dilakukan

\section{Studi pendahuluan}

Tahap persiapan diawali oleh peneliti dengan melakukan studi pendahuluan. Pada penelitian ini peneliti melakukan studi pendahuluan pada tanggal 14 Maret 2014 di wilayah Desa Danguran Klaten Selatan.

2. Penyusunan alat penelitian

Dalam penyusunan alat penelitian menggunakan kuesioner. Sebelum membuat kuesioner peneliti membuat kisi kisi daftar pertanyaan tentang pemanfaatan tanaman obat untuk asam urat untuk mengukur pengetahuan masyarakat
3. Perijinan

Sebelum melakukan penelitian, peneliti menentukan tempat peneliti yang akan dilaksanakan, selanjutnya peneliti mengajukan surat perijinan kepada Kepala Desa Danguran Kecamatan Klaten Selatan

4. Pengambilan data

Pengambilan data dalam penelitian ini dilakukan oleh peneliti, jenis data yang akan digunakan dalam penelitian ini yaitu data primer. Data primer yaitu data yang diperoleh langsung dari responden. Alat pengumpulan data yang digunakan dalam penelitian adalah kuesioner, yaitu sejumlah pertanyaan tertulis yang digunakan untuk memperoleh informasi dari respondendalam arti laporan tentang pribadinya, atau hal - hal yang mereka ketahui (Arikunto, 2013).

Sebelum mengambil data, peneliti meminta bantuan kepada enumenator yaitu Kader dan tokoh masyarakat setelah itu peneliti dan enumenator menyamakan persepsi tentang pemanfaatan tanaman obat untuk asam urat dan cara mengisi kuesioner

\section{Analisis Hasil}

Teknik analisa data yang digunakan:

(1)Menilai masing - masing variabel dengan menggunakan persentase, yaitu :

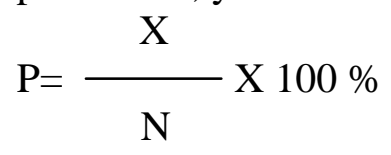

Keterangan :

$\mathrm{P}=$ persentase

$\mathrm{X}=$ jumlah jawaban 
$\mathrm{N}=$ jawaban seluruh item pertanyaan

(2)Menentukan

persentase

kelompok persentase tiap

kelompok problematic, untuk mengetahui respon masuk dalam kategori pengetahuan baik, cukup baik, atau kurang baik. Menurut Arikunto (2013) standarnya adalah sebagai berikut :

a) Mean skor > $75 \%$ kategori pengetahuan ibu PKK baik

b) Mean skor $56 \%$ - $74 \%$ kategori pengetahuan ibu PKK cukup baik

c) Mean skor $<55 \%$ kategori pengetahuan ibu PKK kurang baik

\section{HASIL PENELITIAN}

Alat ukur yang digunakan adalah kuesioner. Dari pengumpulan data analisa data dari kuesioner didapatkan hasil bahwa pengetahuan Ibu PKK tentang pemanfaatan tanaman obat untuk asam urat di Desa Danguran Klaten Selatan termasuk dalam kategori cukup (52\%). Untuk hasil tentang pengertian dalam kategori baik (38\%). Untuk hasil tentang pengetahuan dalam kategori kurang $(10 \%)$

\section{PEMBAHASAN}

1. Karakteristik Responden

Dalam penelitian ini karakteristik responden meliputi umur, tingkat pendidikan dan sumber informasi untuk mengetahui pengetahuan tentang pemanfaatan tanaman obat untuk asam urat. Setelah dilakukan pengumpulan data terhadap 50 orang Ibu PKK Desa Danguran Klaten Selatan diperoleh karakteristik responden sebagai berikut:
Tabel 1

Distribusi Frekuensi Karakteristik

Ibu-ibu PKK Desa Danguran Klaten Selatan Berdasarkan Umur, Pendidikan dan Sumber Informasi

\begin{tabular}{lcc}
\hline \multicolumn{1}{c}{ Kategori } & $\begin{array}{c}\text { Frekuensi } \\
(\mathrm{n}=50)\end{array}$ & $(\%)$ \\
\hline Umur & & \\
\hline$<20$ tahun & 0 & $0 \%$ \\
\hline $20-40$ tahun & 20 & $40 \%$ \\
\hline$>40$ tahun & 30 & $60 \%$ \\
\hline \multicolumn{2}{c}{} & \\
\hline Pendidikan & & $36 \%$ \\
\hline Dasar & 18 & $48 \%$ \\
\hline Menengah & 24 & $16 \%$ \\
\hline Tinggi & 8 & \\
\hline & & $12 \%$ \\
\hline Sumber Informasi & 6 & $36 \%$ \\
\hline Media Cetak & 18 & $52 \%$ \\
\hline $\begin{array}{l}\text { Media } \\
\text { Elektronik }\end{array}$ & 26 & telah
\end{tabular}
dilakukan seperti yang terlihat pada tabel 1 diatas diketahui bahwa karakteristik Ibu PKK Desa Danguran Klaten Selatan berdasarkan umur mayoritas berusia > 40 tahun yaitu sebanyak 30 orang atau sebesar $60 \%$, sedangkan berdasarkan pendidikan diketahui bahwa mayoritas Ibu PKK berpendidikan menengah (SMA atau Sederajat) yaitu sebanyak 24 orang atau sebesar $48 \%$ dan berdasarkan sumber informasi yang diperoleh Ibu PKK tentang pemanfaatan tanaman obat untuk asam urat mayoritas ibu mengetahuinya dari orang lain yaitu sebanyak 26 orang atau sebesar $52 \%$.

2. Pengetahuan Ibu-ibu PKK Desa Danguran Klaten Selatan tentang Pemanfaatan Tanaman Obat Untuk Asam Urat

Berdasarkan hasil analisis data dapat diketahui tingkat pengetahuan Ibu-ibu PKK Desa Danguran Klaten Selatan tentang pemanfaatan tanaman 
obat untuk asam urat seperti yang tersaji pada tabel 2 berikut ini.

Tabel 2

Distribusi Frekuensi Tingkat

Pengetahuan Ibu-ibu PKK Desa

Danguran Klaten Selatan tentang Pemanfaatan Tanaman Obat Untuk Asam Urat

\begin{tabular}{clcc}
\hline No & $\begin{array}{c}\text { Tingkat } \\
\text { Pengetahuan }\end{array}$ & Frekuensi & $(\%)$ \\
\hline 1. & Baik & 19 & 38 \\
\hline 2. & Cukup & 26 & 52 \\
\hline 3. & Kurang & 5 & 10 \\
\hline & Jumlah & 50 & 100 \\
\hline
\end{tabular}

Berdasarkan hasil analisis yang telah dilakukan seperti yang terlihat pada tabel 2 Diatas diketahui secara keseluruhan bahwa tingkat pengetahuan ibu-ibu PKK Desa Danguran Klaten Selatan mayoritas termasuk dalam kategori berpengetahuan cukup yaitu sebanyak 26 orang atau sebesar $52 \%$.

3. Pengetahuan Ibu-ibu PKK Desa Danguran Klaten Selatan tentang Pemanfaatan Tanaman Obat Untuk Asam Urat Berdasarkan Karakteristik Responden

Pengetahuan Ibu-ibu PKK Desa Danguran Klaten Selatan tentang pemanfaatan tanaman obat untuk asam urat berdasarkan karakteristik menurut umur, pendidikan dan sumber informasi yang mereka peroleh tentang pemanfaatan tanaman obat untuk asam urat dapat dilihat pada tabel 3 berikut ini.

Tabel 3

Cross Tabulation (Tabulasi Silang)

Pengetahuan Ibu-ibu PKK Desa

Danguran Klaten Selatan tentang

Pemanfaatan Tanaman Obat Untuk Asam Urat Berdasarkan

Karakteristik Ibu-ibu PKK Desa Danguran Klaten Selatan

\begin{tabular}{|c|c|c|c|c|c|c|c|c|}
\hline \multirow{2}{*}{$\begin{array}{l}\text { Tingkat } \\
\text { Pengetahuan } \\
\text { Umur }\end{array}$} & \multicolumn{2}{|c|}{ Baik } & \multicolumn{2}{|c|}{ Cukup } & \multicolumn{2}{|c|}{ Kurang } & \multicolumn{2}{|c|}{ Jmlh } \\
\hline & $f$ & $\%$ & $f$ & $\%$ & $\mathrm{f}$ & $\%$ & $\Sigma \mathrm{f}$ & $\begin{array}{l}\Sigma \\
\%\end{array}$ \\
\hline $\begin{array}{l}20-40 \\
\text { tahun }\end{array}$ & 12 & 24 & 8 & 16 & 0 & 0 & 20 & 40 \\
\hline $\begin{array}{l}>40 \\
\text { tahun }\end{array}$ & 7 & 14 & 18 & 36 & 5 & 10 & 30 & 60 \\
\hline Jumlah & 19 & 38 & 26 & 52 & 5 & 10 & 50 & $\begin{array}{l}10 \\
0\end{array}$ \\
\hline \multicolumn{9}{|l|}{ Pendidikan } \\
\hline Dasar & 0 & 0 & 13 & 26 & 5 & 10 & 18 & 36 \\
\hline $\begin{array}{l}\text { Meneng } \\
\text { ah }\end{array}$ & 11 & 22 & 13 & 26 & 0 & 0 & 24 & 48 \\
\hline Tinggi & 8 & 16 & 0 & 0 & 0 & 0 & 8 & 16 \\
\hline Jumlah & 19 & 38 & 26 & 52 & 5 & 10 & 50 & $\begin{array}{l}10 \\
0\end{array}$ \\
\hline \multicolumn{9}{|l|}{$\begin{array}{l}\text { Sumber } \\
\text { Informasi }\end{array}$} \\
\hline $\begin{array}{l}\text { Media } \\
\text { Cetak }\end{array}$ & 4 & 8 & 2 & 4 & 0 & 0 & 6 & 12 \\
\hline $\begin{array}{l}\text { M. } \\
\text { Elektron } \\
\text { ik }\end{array}$ & 13 & 26 & 5 & 10 & 0 & 0 & 18 & 36 \\
\hline $\begin{array}{l}\text { Orang } \\
\text { Lain }\end{array}$ & 2 & 4 & 19 & 38 & 5 & 10 & 26 & 52 \\
\hline Jumlah & 19 & 38 & 26 & 52 & 5 & 10 & 50 & $\begin{array}{l}10 \\
0\end{array}$ \\
\hline
\end{tabular}

Dari tabel 3 di atas dapat diketahui bahwa pengetahuan Ibu PKK Desa Danguran Klaten Selatan berdasarkan karakteristik menurut umur mayoritas berumur $>40$ tahun dalam kategori cukup sebanyak 18 orang atau sebesar 36\%. Pengetahuan ibu-ibu PKK Desa Danguran Klaten Selatan berdasarkan karakteristik menurut pendidikan mayoritas ibu-ibu PKK berpendidikan menengah dalam kategori tingkat pengetahuan cukup sebanyak 13 orang atau sebesar $26 \%$. Tingkat pengetahuan ibu-ibu PKK Desa Danguran Klaten Selatan berdasarkan karakteristik menurut sumber informasi yang diperoleh Ibu PKK Desa Danguran Klaten Selatan mayoritas memperoleh sumber informasi tentang pemanfaatan tanaman obat untuk asam urat dari orang lain termasuk ke dalam kategori tingkat pengetahuan cukup sebanyak 19 orang atau sebesar $38 \%$. 


\section{KESIMPULAN DAN SARAN}

Berdasarkan hasil penelitian yang dilakukan Di Desa Danguran Klaten Selatan tentang pengetahuan Ibu PKK pemanfaatan tanaman obat untuk asam urat di Desa Danguran Klaten Selatan dapat diambil kesimpulan bahwa :

1. Pengetahuan Ibu PKK pemanfaatan tanaman obat untuk asam urat di Desa Danguran Klaten Selatan Dalam kategori cukup yaitu sebanyak 26 orang atau sebesar $(52 \%)$.

2. Karakteristik berdasarkan sumber informasi paling banyak di dapatkan adalah berasal dari orang lain $(52 \%)$ dan media cetak $(36 \%)$.

3. Karakteristik berdasrkan umur Ibu PKK di Desa Danguran prosentase paling banyak adalah berusia $>40$ tahun yaitu sebanyak 30 responden $(60 \%)$

\section{DAFTAR RUJUKAN}

Arikunto, 2006.Prosedur Penelitian Suatu Pendekatan

Praktek.Jakarta: Rineka Cipta

Arikunto,2013.Prosedur

penelitian.Jakarta : Rineka Cipta

Depkes RI, 2010. Penuntun Hidup Sehat. Jakarta : Depkes RI

Notoatmodjo, 2010. Metode Penelitian. Jakarta : Rineka Cipta

Soeroso, 2011. Asam Urat.Depok : Penebar Plus

Sugiyono,2011.Metode Penelitian Kuantitatif dan R\&D.Bandung : Alfa Beta

Susiarti, 2009. Pengetahuan Masyarakat Pekurehua Di Sekitar Taman Nasional Lore Lindu, Sulawesi Tengah Tentang Tumbuhan Obat Dan Pemanfaatannya. Jurnal Bahan Alam
Utami dan Lentera, 2008. Tanaman Obat Untuk Mengatasi Rematik \& Asam Urat. Jakarta : AgroMedia Pustaka

Utami dan Lentera, 2009. Solusi Sehat Mengatasi Asam Urat Urat \& Rematik. Jakarta : AgroMedia Pustaka 